\title{
SARS-CoV-2 / COVID-19 and its Transmission, Prevention, Treatment and Control - An Update
}

\author{
Pooja Sharma ${ }^{1} \mathbb{D}$, Sonam Tripathi ${ }^{1}$ (D) Shailesh Kumar Patel ${ }^{2}$, \\ Kuldeep Dhama² ${ }^{\text {DD }}$ and Ram Chandra ${ }^{1 *}$
}

${ }^{1}$ Department of Environmental Microbiology, School for Environmental Sciences Babasaheb Bhimrao Ambedkar Central University, Vidya Vihar, Rae Bareli Road, Lucknow, Uttar Pradesh - 226025, India. ${ }^{2}$ Division of Pathology, ICAR-Indian Veterinary Research Institute, Izatnagar, Bareilly - 243 122, Uttar Pradesh, India.

\begin{abstract}
Coronavirus Disease 2019 (COVID-19), caused by Severe Acute Respiratory Syndrome Virus-2 (SARSCoV-2), pandemic has caused huge panic, havoc and global threats worldwide. The origin of this virus has been linked to animals, intermediate host is still to be identified, and studies are being carried out that how it got transmitted to humans and acquired rapid human-to-human transmission. Within a short time period of only 05 months, SARS-CoV-2 has spread to 213 countries, and till 28th May, 2020, nearly 5.8 million confirmed cases have been reported while taking lives of 0.36 million persons. Seeing the current situation of rapid increase in COVID-19 cases daily in many countries, this seems to be the deadliest pandemic after the 1918 Spanish Flu. There is currently no specific effective treatment for COVID-19 and also in absence of vaccine the radical cure of the disease is far away. Researchers are pacing high to design and develop effective vaccines, drugs and therapeutics to counter COVID-19, however such efforts, clinical trials, necessary approvals and then to reach the level of bulk production of many millions of doses may still take much time. Prevention and control of COVID-19 outbreaks requires an evidence-based, multi-factorial and effective mitigation strategy to be adopted. The current review discusses on the research advancements, challenges and opportunities in COVID 19 management with a focus on its transmission, prevention, treatment and control.
\end{abstract}

Keywords: COVID-19, SARS-CoV-2, transmission, prevention, treatment, control

*Correspondence: prof.chandrabbau@gmail.com

(Received: April 24, 2020; accepted: May 28, 2020)

Citation: Sharma P, Tripathi S, Patel SK, Dhama K, Chandra R. SARS-CoV-2 / COVID-19 and its Transmission, Prevention, Treatment and Control - An Update. J Pure Appl Microbiol. 2020;14(suppl 1):945-956. doi: 10.22207/JPAM.14.SPL1.32

C The Author(s) 2020. Open Access. This article is distributed under the terms of the Creative Commons Attribution 4.0 International License which permits unrestricted use, sharing, distribution, and reproduction in any medium, provided you give appropriate credit to the original author(s) and the source, provide a link to the Creative Commons license, and indicate if changes were made. 


\section{INTRODUCTION}

A novel coronavirus named as Severe Acute Respiratory Syndrome Virus-2 (SARS-CoV-2), the causative agent of Coronavirus Disease 2019 (COVID-19), emerged in Wuhan, China in December month of the last year (2019). It attained the status of public health emergency of international concern on January 30, 2020, and later on March 11, 2020 was declared as a global pandemic by World Health Organization ${ }^{1}$. The International Committee on Taxonomy of Viruses (ICTV) recognized the virus as SARSCoV-2 (earlier known as nCoV-2019) and the disease was named as coronavirus disease 2019 (COVID-19) by $\mathrm{WHO}^{2}$. The virus has now caused huge panic and very high global threats to the lives of mass population across the globe. The global risk of COVID-19 is increasing progressively for the general public and considered to be very high for the communities with identified risk factors. The virus appears to be highly infectious and has spread rapidly throughout the globe. A meeting was held on this issue on $30^{\text {th }}$ January 2020 under the International Health Regulations (IHR, 2005) and WHO declared the outbreak as Public Health Emergency of International Concern (PHEIC) because it had spread to 18 countries with four countries reporting human-tohuman transmission. Currently, nearly 06 million individuals from 213 countries and territories are affected from the SARS-CoV-2 infection with over 0.35 million deaths worldwide ${ }^{3}$. Presently, the USA, Brazil, Russia, Spain, UK, Italy, France, Germany, Turkey and India are among the list of top 10 COVID-19 affected countries, which overload the healthcare system due to high patient burdens needing intensive care and treatment. As on $28^{\text {th }}$ May, 2020, 4,534 deaths out of a total of 1,58,086 confirmed cases of COVID-19 have been reported from India ${ }^{4}$.

Moreover, earlier coronaviruses (CoVs) viz. Severe Acute Respiratory Syndrome coronavirus (SARS-CoV) and Middle East Respiratory Syndrome coronavirus (MERS-Cov) also induced lethal outbreaks but the currently ongoing SARS-CoV-2 pandemic is the deadliest among all the zoonotic CoVs. On 20 January 2020, China announced the disease as a second-class infectious disease, but followed prevention and control strategies for the first-class infectious disease, the most risky category of infectious diseases 5 . The COVID-19 was first reported as pneumonia of unknown origin in China and then spread like wildfire to the rest of the world, posing a noteworthy global threat to the public health globally ${ }^{6,7}$. Presently, there is no effective vaccine or treatment option available for COVID-19, and for this purpose high efforts are continuously being made by researchers from many countries.

In particular, reports showed that 2 $\%$ population are healthy carriers of CoVs and these viruses contribute for 5 to $10 \%$ of acute respiratory infections. A total of seven CoVs have been reported to infect human's viz., HCoV229E, HCoV-NL63, HCoV-HKU1 and HCoV-OC43, capable of causing mild respiratory symptoms alike to that of common cold, while SARS-CoV-2, SARS-CoV and MERS-CoV have been associated with fatal infections ${ }^{8,9}$. SARS-CoV (2003) has previously infected 8096 people with 774 deaths at a case fatality rate of $9.6 \%$ around the world, although the rate of survival is higher among the COVID-19 patients but the rate of infection is growing exponentially which may have a larger impact. Even though COVID-19 is spreading rapidly through airborne route, air disinfection of towns and communities was not found to be effective enough in disease control. This review presents current knowledge and advances on SARSCoV-2 / COVID-19 management and specifically highlighting its transmission, prevention and control strategies.

\section{Characteristics of SARS-CoV-2}

Coronaviruses (CoVs) belong to the family Coronaviridae in the order of Nidovirales. The SARS-CoV-2 represents crown-like spikes on the envelope of the virus; hence named coronavirus ${ }^{10}$. Coronavirinae consists of four main sub-groupings / genera, Alpha-, Beta-, Gamma- and Deltacoronavirus, and that the first two host human infecting viruses (Human Coronavirus, HCoV): HCoV-229E and HCoV-NL63 (alpha coronavirus) and HCoV-HKU1, HCoV-OC43, Middle East coronavirus respiratory syndrome (MERS-CoV), extreme acute coronavirus respiratory syndrome (SARS-CoV) (beta coronavirus) ${ }^{11,12}$. The CoVs including the SARS-CoV-2 have a non-segmented, single stranded, positive sense RNA genome of around $30 \mathrm{~kb}^{11,13}$ (Fig. 1). The SARS-CoV-2 is a member of the sub-family Orthocoronavirinae 
under the family Coronavirida ${ }^{14}$. On the basis of molecular characterization, the virus has been reported to be a new betacoronavirus that belongs to the subgenus Sarbecovirus ${ }^{14}$. An overall $80 \%$ identity between SARS-CoV-2 and SARS-CoV along with $89 \%$ identity with two bat SARS related CoVs (ZC45 and ZXC21) has been reported at nucleotide level ${ }^{13,15}$. The structural proteins of CoVs are encoded by four structural genes, including spike (S), envelope (E), membrane (M) and nucleocapsid $(\mathrm{N})$ genes. The $\mathrm{S}$ protein makes the spike on the virion surface and is responsible for the binding with host cell receptor ${ }^{16,17,13}$. The SARSCoV-2 has a typical coronavirus structure with $S$ protein and also expresses other polyproteins, nucleoproteins and membrane proteins including RNA polymerase, 3chymotrypsin-like protease, papain-like protease, helicase, glycoprotein and accessory proteins ${ }^{18}$.

The entire mechanism of SARS-CoV-2 pathogenicity, from entry, attachment to replication, is presented in Fig. 1 . Viruses use the large network of host cell signalling pathways to facilitate their replication and spread (propagation). Each encoded viral protein has a distinct structural role and also get associated in other mechanisms of the replication cycle. Unlike other major structural proteins, $\mathrm{N}$ protein functions mainly to bind to CoV RNA genome, rendering it a nucleocapsid ${ }^{19}$. Moreover, in virus-infected cells, $\mathrm{N}$ protein of the CoVs may be clustered either to the cytoplasm alone or to the cytoplasm and nucleolus. The $M$ protein is the most copious structural protein that determines the structure of the viral envelope ${ }^{20}$. The endoplasmic reticulum (ER) can maintain a high protein content without getting weighed down. Furthermore, once the ER folding and dealing out protein capacity is overloaded, the unfolded proteins swiftly build up in lumen and ER stress reaction is activated ${ }^{21}$. This is also known to be the main organizer of the coronavirus group, communicating with all other large structural corona viral proteins. The ORF1ab as the largest gene in SARS-CoV-2 encodes pplab and 15 nsps. The ORF1a gene encodes pp1a protein, contains $10 \mathrm{nsps}^{22}$. SARS-CoV-2 also utilizes the same ACE2 (angiotensin-converting enzyme 2) cell receptor and host cell entry mechanism as used by SARS$\mathrm{CoV}^{15}, 23$. The single mutation of N501 T in SARSCoV-2 Spike protein might have notably improved its binding affinity to ACE2 receptor ${ }^{24}$.

\section{COVID-19: The Disease}

Individuals diagnosed with SARS-CoV-2 show symptoms of different classes from fever or mild cough to pneumonia and severe involvement of various organ dysfunctions with a mortality rate from $2 \%$ to $4 \%$. In general, the SARS-CoV-2 causes fever, dry cough, generalized weakness, respiratory distress, muscle ache, rhinorrhoea, pleuritic chest pain and to some extent headache, nausea, vomition, haemoptysis and diarrhoea ${ }^{25,13,7}$. A range of sickness in children has been reported from SARS-CoV-2 infection ${ }^{26}$. SARS-CoV-2 has also been implicated in causing damaging effects on the central nervous system (CNS) as observed while investigating viral encephalitis $\operatorname{cases}^{27,28}$. Systemic Inflammatory Response Syndrome (SIRS) may well be unusually triggered in severe pneumonia caused by CoV disease, although early anti-inflammatory treatments can effectively prevent immune damage and reduce the impact of damage to the nervous system ${ }^{29,30}$. Moreover, the rampant inflammation in response to SARSCoV-2 infection resulted into cytokine storm associated with release of pro-inflammatory cytokines and chemokines like IFN- $\gamma$, IL-1 $\beta$, IP-10, MCP-1, TNF- $\alpha$, G-CSF, MCP-1, IP-10, and MIP-1A, which is reported to severely damage the pulmonary tissues and leads to death in severe COVID-1931,32. The blood profile of the COVID-19 affected individuals exhibits leukopenia, lymphopenia, thrombocytopenia, RNAaemia along with increased hypersensitive troponin I and aspartate aminotransferase levels? ${ }^{7}$. In subregions of Italy, SARS-CoV-2 infection got more widely spread in elderly people. The associated clinical presentation include fever, cough, malaise and acute respiratory distress syndrome (ARDS), which is reported to be a major cause of increased mortality among these immunocompromised patients $13,33,34$.

\section{Transmission and Spread}

According to the WHO, viral diseases will go on emerging and pose grave public health concerns globally. Many viral epidemics in the $21^{\text {st }}$ Century, including SARS in 2002 to 2003, Influenza (H1N1) in 2009 and MERS in 2012, and recent episodes of Ebola, Zika, Nipah have been reported ${ }^{35}$. The role animals and zoonotic links have been implicated in the origin of SARS- 
CoV-2 ${ }^{36}$. The first cases of COVID-19 were related to direct contact with animals available for sale in Huanan Seafood Wholesale Market in Wuhan and the animal-to-human transmission was reported to be the key mechanism, and thereafter SARSCoV-2 might have acquired human-to-human transmission ${ }^{37,36}$. Although, people of all possible age groups and physiological condition are susceptible for the SARS-CoV-2 infection but the old people and those with immune-compromised state are at the greater risk $^{13,33,7}$. In addition, healthcare professionals are also prone for the nosocomial infection of SARS-CoV- $2^{7}$.

The virus is mainly transmitted by contact with infected person as a resulted of human-to-human and nosocomial transmission via virus laden aerosols, contaminated surfaces or hands $s^{7,38,39}$. The disease is reported to spread in several stages like stage one, in which the disease is imported by travellers from foreign countries and does not spread locally. In stage two, local transmission occurs via a patient who has travelled outside the country to family members or other people who have been in close contact with the infected person took place. In stage three, the virus spreads rapidly and largely by community transmission, in which the infected individual can't be traced and isolated. Moreover, those who have not been exposed to a traveller from affected country or an infected individual may also test positive for the coronavirus in stage 3 and the rapid transmission in clusters starts ${ }^{40}$. Coronavirus outbreak: What are the stages of transmission and what they mean, $2020^{41}$. The Stage 4 is the most dreaded stage in which the disease becomes an epidemic in a country with huge numbers of infections and a heavy death toll with no end in sight ${ }^{42}$.

The coronaviruses from droplets and body fluids of infected individuals are likely to remain infectious for a period of 9 days on contaminated surfaces leading to spread via mucous membranes of the eyes, nose or mouth by self-inoculation ${ }^{43,44}$. Further, human-to-human transmission via eyes was reported earlier and exposure of unprotected eyes to the SARS-CoV-2 may increase the risk of transmission via ocular route as observed in SARS-CoV infection ${ }^{45,46}$. Additionally, the SARSCoV-2 is reported to be present in the stool of COVID-19 patient, suggesting the probability of faeco-oral route to be another potential route for transmission of this virus ${ }^{47}$. The main source of the transmission of SARS-CoV-2 is by respiratory droplets released during coughing or sneezing of the infected patient. The asymptomatic or mildly symptomatic individuals are the major hurdles in identifying the transmission chains and its subsequent tracing resulting into further transmission ${ }^{48}$.

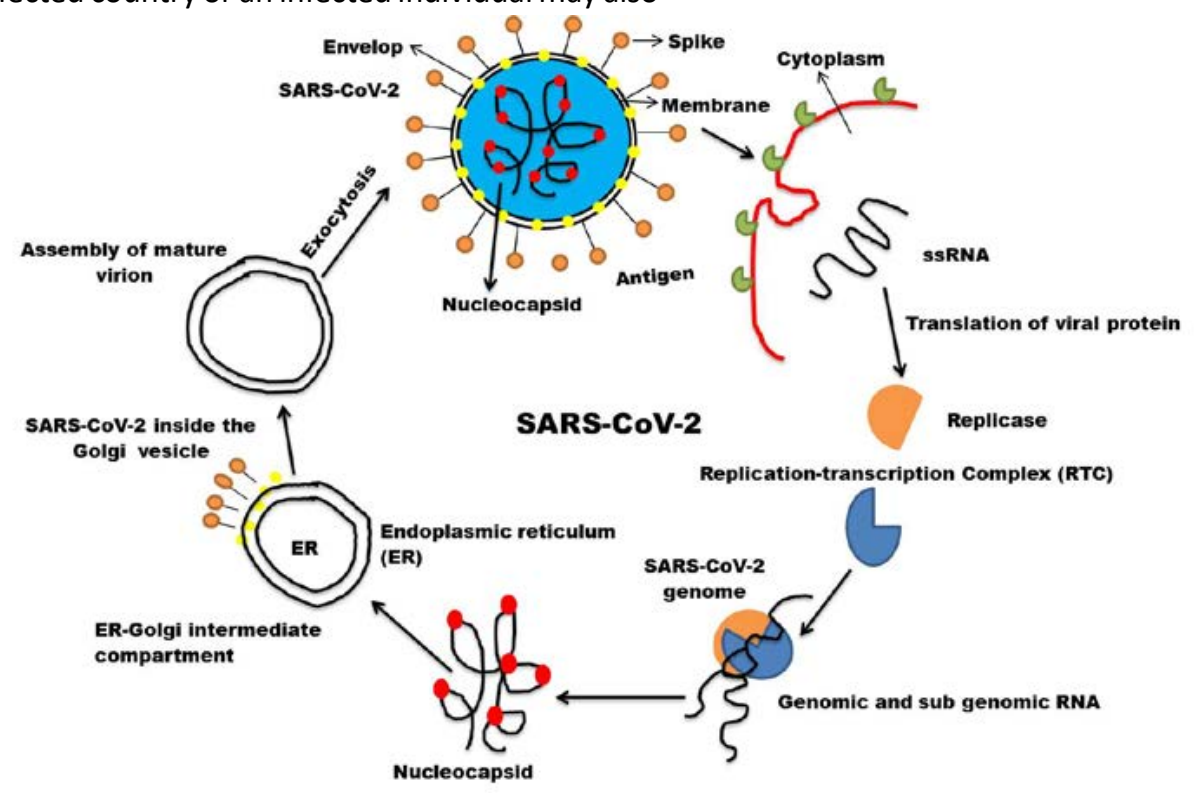

Fig. 1. Replication of SARS-CoV-2 
Environmental circumstances like temperature appear to have an effect on the ability of CoV to survive in water. Further studies are required to examine the persistence of $\mathrm{CoV}$ in water in relation to climatic and seasonal conditions ${ }^{49}$. SARS-CoV-2 has been reported to be found in patient's fecal and anal swabs and the risk of fecal-oral transmission including water-borne transmission need to be studied and explained ${ }^{49}$. SARS-CoV-2 viral RNA has been detected in wastewater of hospital isolation wards and sewage water, which has high public health concerns, and therefore appropriate surveillance and treatment of wastewater need to be followed to avoid mass transmission and spread of COVID-19 $9^{50-52}$. Hence to minimize the possibility of false negative results during the preliminary screening, faecal samples must be tested as a complementary method for initial diagnosis of COVID-19. In this context, COVID-19 confirmed cases should only be declared as negative when oropharyngeal samples along with faecal samples were tested negative because prolonged viral shedding was reported even in cured patients suggesting the potential possibility of unintentional fecal-oral transmission ${ }^{53}$. Moreover, the collection of faecal sample is a non-invasive method and can be performed easily by the patient itself preventing the possibility of nosocomial transmission too ${ }^{54}$. Data analysis relevant to the spread of SARSCoV-2 in China appears to suggest that close communication between individuals is important for transmission. In addition, the distribution is mainly limited to family members, health professionals as well as other close contacts. Previously reported histopathological information on the lungs of 02 patients subjected to lung lobectomy for adenocarcinoma, revealed an infection at the time of surgery, supporting the phenomenon of nosocomial infection ${ }^{55}$.

There have been studies of new-born babies tested positive for COVID-19 after birth from mothers who have also been tested positive for COVID-1956. Wei et al. (2020) ${ }^{57}$ reported that children of all the ages, such as new-born babies and young children may also be infected. Furthermore, having COVID-19 while pregnancy may still have an impact on the fetal outcome, including fetal distress, potential preterm birth and breathing difficulties ${ }^{58}$.
Necessary risk assessment of the pandemic

Increased duration of hospitalization, ICU bed occupation and ventilators requirements by COVID-19 patients is a major issue of concern for the countries facing the pandemic. We have learned more about how COVID-19 affects people as the pandemic is advancing. The older people suffering from chronic illnesses such as diabetes, heart disease, are at higher risk of severe COVID-19 problems ${ }^{59}$. This virus also severely affects children below 5 years of age having compromised immune system. We know that people of any age may be infected with the virus but the mortality is very high in people with comorbidities especially of older age group. In absence of an effective radical cure, large scale testing, lock down and social distancing is the only ray of hope till date. People might also be infected by touching surfaces infected with the virus followed by touching their face, eyes, nose and mouth without taking the necessary preventive steps.

Latest reports of COVID-19 infectious diseases demonstrated that the both communitydwelling senior citizens as along with those in assisted living facilities, nursing homes and other congregated living facilities would be at greater risk of the SARS-CoV-2 infection ${ }^{60}$. Moreover, emergency concerns which need to be discussed include whether pregnant women with COVID-19 diagnosed pneumonia can experience distinct symptoms from non-pregnant adults, and are also much more likely to die from infection or undergo preterm labour, and COVID-19 could spread vertically and cause risks to the foetus and neonate ${ }^{61}$.

People at high-risk are as follows:

- $\quad$ Living with someone who has contracted the virus.

- $\quad$ Providing home treatment to someone who has contracted the virus.

- Maintain distance from person who has contracted the virus and also some appropriate distance in home.

- Immunocompromised, having other illnesses, elderly and young children.

- $\quad$ Consult a doctor if symptoms of COVID-19 seems to be started.

- Do not delay in getting medical treatment besides your underlying illnesses condition. Serious heart diseases, like heart problems, 
coronary artery disease, congenital heart disease, lung cancer, and pulmonary hypertension, can put patients at greater risk for severe COVID-19.

- $\quad$ Older people (65 years) are at greater risk of severe illness and death from COVID-19.

- Young children are at greater risks of acquiring severe COVID-19.

- Some conditions and therapies may cause some people to get a weak immune system, such as cancer treatment, bone marrow or organ transplantation, immune deficiencies, low CD4 cell count in HIV, prolonged use of corticosteroids and other immune disabling drugs, putting at high risk of COVID-19.

- Haemoglobin disturbances like sickle cell disease (SCD) and thalassemia can put patients at greater risk for a severe disease owing to COVID-19.

- Diabetes, like type 1 , type 2 or gestational, put patients at greater risk of a serious illness due to COVID-19.

- $\quad$ Chronic lung and kidney disease, including chronic obstructive pulmonary disease (COPD) idiopathic pulmonary fibrosis and cystic fibrosis, could put people at higher risk of COVID-19

Pregnant women are at greater risk owing to scarcity of information regarding possibility of in-utero infection of the SARS-CoV-2, therefore a thorough systematic examination of SARS-CoV-2 infected pregnant women and further follow up screening is utmost necessary ${ }^{62}$.

\section{Treatment and control}

There is currently no vaccine available for COVID19 and a vaccine may take more than a year to be available widely even after the great efforts were being made by the researchers of different countries in order to develop them. Additionally, considering the rapid pace of vaccine development, one can assume that we are not too far from our goal to develop an effective vaccine against the SARS-CoV- $2^{63}$. Moreover, some of the signs and symptoms could be treated and early care by a healthcare provider can make the disease less risky. Several potential specific therapies, drugs and medicines are being explored as well as their clinical trials are underway in the search of possible treatment for COVID-1964,65. The
WHO, CDC and FAO have released guidelines and COVID-19 safety measures for common people, physicians, travellers and infectious patients to avoid risk of transmission and spread to a healthy individual ${ }^{6-68}$. Governments of different nations are advising travellers to defer their tours in order to prevent contact to COVID-19 affected countries, and persons coming back from affected countries are being isolated, quarantined and monitored for health check-ups as well as screened for SARS-CoV-2 so as to avoid further spread to other persons ${ }^{69-71}$. It has been reported that the CoVs may be inactivated on contaminated surfaces or inanimate objects by treatment with biocidal agents, like $62-71 \%$ ethanol, $0.5 \%$ hydrogen peroxide and $0.1 \%$ sodium hypochlorite disinfectants for a minimum period of 1 minute ${ }^{38}$.

The antiviral therapy commonly used against CoVs globally includes antiviral like ritonavir, ribavirin, lopinavir and interferons or their combination ${ }^{72}$. However, the antivirals like acyclovir, oseltamivir, zanamivir, paramivir, ganciclovir and ribavirin used for the treatment of viral infections are not recommended for COVID-19 treatment ${ }^{73}$. A combination of ritonavir and lopinavir commonly used for treatment of the human immunodeficiency virus (HIV) showed promising results in case of SARS and MERS but the safety and efficacy of this combination in COVID-19 is being evaluated ${ }^{74,75,7,73,76}$. In addition, the ritonavir and lopinavir combination was recommended against SARS-CoV-2 infection in China during the early stages of the pandemic ${ }^{77,78}$. The remdesivir (A nucleotide analogue) was reported to be administered in Ebola virus patients and has also been proved effective against the coronavirus ${ }^{79}$. Studies have also reported that certain other medications could be used for potential effectiveness in the treatment of COVID-19, such as darunavir, a second generation HIV-1 protease inhibitor. Second is transmembrane type II serine protease (TMSPSS2) inhibitors and $B C R-A B L$ imatinib kinase inhibitor. Imatinib has anti-corona activity mainly as it prevents fusion of virions with the membrane of the endosoma ${ }^{80}$. Favipiravir is a new RNA-dependent sort inhibitor of RNA polymerase (RdRp) in COVID-1981. Additionally, therapeutics like arbidol (umifenovir), tenofovir disoproxil (TDF), lamivudine (3TC), RNA synthesis inhibitors, hormones and conventional 
Chinese capsules viz. Lianhuaqingwen and ShuFengJieDu were also reported to be widely used against SARS-CoV-2 but their efficacy needs to be determined by in-vivo and in vitro trials ${ }^{76}$.

The chloroquine phosphate (anti-malarial drug) was reported to be the first drug found effective against the SARS-CoV-2 in China ${ }^{82}$. Additionally, the chloroquine was included in the "Guidance for Corona Virus Disease 2019: Chloroquine was used in earlier in vitro studies to block a low-micro molar infection of SARSCoV-2 concentration, with a half-maximum efficiency concentration $\left(\mathrm{EC}_{50}\right.$ ) of $1,13 \mu \mathrm{M}$ and half-cytotoxicity concentrations $\left(\mathrm{CC}_{50}\right)$ greater than $100 \mu \mathrm{M}^{83}$. Due to the easy availability and low cost of the chloroquine and its analogue viz. hydroxychloroquine these drugs may prove crucial to contain the SARS-CoV-2 after proper efficacy and safety evaluation by clinical trials. Moreover, a study also hypothesized the synergistic and consequential effect of hydroxychloroquine and ivermectin for chemoprophylaxis along with clinical care of SARS-CoV-2 infection upon simultaneous administration ${ }^{84}$. Artificial intelligence technology is being exploited to recognize repurposed drugs and medicines having potent prospective in therapeutic application for countering COVID-1985. Antibodies-based immunotherapies such as monoclonal antibodies (mAbs), neutralizing antibodies (NAbs), intravenous immunoglobulin (IVIg), and the use of convalescent plasma therapy are also good options which are being explored to counter COVID-1986-88.

The host-directed therapies like glitazones, metformin, fibrates, sartans, atorvastin, nutrient supplements and zinc based supplements along with other drugs with a good safety profile may also be used against SARS-CoV-2 as an alternative treatment option ${ }^{89}$. Studies have so far been demonstrated many agents, such as Western medicines, natural products, traditional Chinese medicines, plants and herbs for use in possible prevention and treatment against COVID-1981, 65, ${ }^{90}$. Changes in dietary habits during the epidemic COVID-19 may also be motivated by fear and anxiety ${ }^{91}$. Apart from searching for anti-viral drugs and vaccines, choosing appropriate food systems, having balanced foods in regular diets, incorporating herbs and traditional medicines, and sufficient amount of dietary zinc and vitamins $A, C$,
E, B6 and B12 are essential for the maintenance of better immune function to fight against COVID-19 92, 65. Yoga and health exercises are also helpful to maintain the biological function and enhance the immunity.

In the current scenario of lack of any vaccine or drug, adopting early and rapid diagnosis, following appropriate isolation and quarantine policies, enhancing viral surveillance and monitoring, and adopting strict prevention, control and mitigation strategies are the main options to counter COVID-19. Researchers are pacing high to design and develop effective vaccines and potent drugs / therapeutics to fight against SARS-CoV-2 / COVID-19 pandemic ${ }^{9,93}$.

Public health measures are routine preventive measures, such as:

- $\quad$ Staying home and being isolated when sick.

- $\quad$ Cover the mouth and nose with flexed elbows or tissue while coughing or sneezing.

- Wash your hands often with soap and water, and apply appropriate sanitizer.

- Apply enough soap to cover your moist hands, clean all the sides of the hands, such as the backs of the hands, between the fingers and under the nails.

- If you have cough, asthma, trouble breathing, seek medical attention.

- $\quad$ Avoid close contact with people who are ill, even inside your family.

- $\quad$ Be careful that even those people with no symptoms may be able to transmit the COVID-19.

- Install Apps such as Arogya Setu app for knowing the current contact people who positive from COVID-19 disease. For selfprotection, awareness and stop community transformation of COVID-19.

In severely affected countries, social distancing strategies need to be followed strictly, staying at home during lock down period; avoid mass gatherings, cancel or postpone major public events, marriages, and other social functions, closing down of schools, colleges and universities, shopping malls, government offices, libraries, museums, work places, factories and public transport systems.

Basic Concepts of avoiding SARS-CoV-2 infection in schools

Basic principles will help keep children, 
teachers and staff healthy at school and help to prevent and avoid transmission and spread of this disease. Guidelines for safe practices at schools are as follows:

- Schools should ensure routine hand washing with clean soap and water, alcohol rub / hand sanitizer or chlorine solution and frequent disinfection and sanitation of school premises and surfaces.

- $\quad$ Sick teachers, students and other employees must not be allowed to come.

- Schools should have ample water, sanitation and waste disposal services and must follow policies for cleaning and disinfection of the school building.

- Schools can encourage social distancing and the restriction should be imposed on large gathering.

- If soap and water are not easily accessible, an alcohol-based sanitizer with at least $60 \%$ alcohol may be employed.

- Wash your hands with soap and ample of water while hands appear visibly dirty.

Promote information sharing

- $\quad$ Organize and follow the instructions and advisories of the national health and educational authorities.

- Share known information with staff, caregivers and students, provide up-todate information on the disease condition, including treatment and prevention activities at schools.

- Reinforce the guardians to inform the school and health authorities if anyone at home is found infected, then ask them not to send the child to school.

- Use parent-teacher committees and other systems to encourage sharing of information. Always ensure that children's problems and issues are properly addressed, implementation of child-friendly resources, like display of posters on notice boards, in toilets, and other key locations may be helpful.

\section{CONCLUSION}

The current compilation presents an overview on the good knowledge and recent advances related to SARS-CoV-2 /COVID-19. The SARS-CoV-2 is spreading rapidly around the globe leaving the world population in a stage of fear and huge mental trauma in the absence of any effective vaccine and therapy. Moreover, the SARS-CoV-2 is posing high global public health threats due to its highly infectious nature, rapidly increase in cases and deaths worldwide, and complex pathogenesis which is not fully understood till date. Although many drug regimens are in wide use in order to reduce the death toll and providing appropriate clinical care to the infected individuals but the search of a specific and effective therapeutic agent is needed at earliest possible time in coming future. Additionally, many companies and research institutes are on the way of vaccine development to contain this ongoing pandemic putting their best possible efforts ahead. However, prevention of the infection by social distancing and following recommended precautionary measures is the only option to stop further spread of the COVID-19 till an effective vaccine and therapy is not available. Globally, researchers, scientists, different health organizations and agencies are working days and nights with high efforts to halt further transmission and spread of this pandemic virus by following strict awareness, prevention and mitigation strategies, and improved treatment and supportive care policies. There is an urgent need of appropriate treatment for symptomatic relief to the individuals and to reduce the burden of transmission in order to minimize the infection. In addition, better understanding of COVID-19 pathogenesis, viral replication and transmission dynamics along with developing effective vaccines, drugs and therapeutics will pave the way to end this pandemic soon.

\section{ACKNOWLEDGMENTS}

All the listed author(s) are thankful to their representative universities/institutes for providing the related support to compile this work.

\section{CONFLICT OF INTEREST}

The authors declare that there is no conflict of interest.

\section{AUTHORS' CONTRIBUTION}

All the listed author(s) have made a substantial, direct, and intellectual contribution to the work, and approved it for publication. 


\section{FUNDING}

None.

\section{ETHICS STATEMENT}

This article does not contain any studies with human participants or animals performed by any of the authors.

\section{AVAILABILITY OF DATA}

Not applicable.

\section{REFERENCES}

1. WHOa. Novel coronavirus (2019-nCoV) situation report 11. Jan 31, 2020. https://www.who.int/docs/ defaultsource/coronaviruse/situationreports/20200131sitrep-11-ncov.pdf?sfvrsnde7c0f74 (accessed Feb 18, 2020)

2. Gorbalenya AE. Severe acute respiratory syndrome-related coronavirus-The species and its viruses, a statement of the Coronavirus Study Group. BioRxiv. 2020;5:536-544 https:/doi.org/10.1101/2020.02.07.937862

3. https://gisanddata.maps.arcgis.com/apps/opsdashboard /index.html\#/bda7594740fd40299423467b48e9ecf6

4. https://www.covid19india.org/

5. Xiao $\mathrm{Y}$, Torok ME. Taking the right measures to control COVID-19. The Lancet Infectious Diseases. 2020;20:523524

6. Deng SQ, Peng HJ. Characteristics of and public health responses to the coronavirus disease 2019 outbreak in China. Journal of Clinical Medicine. 2020;9:575. https:/ doi.org/ 10.3390/jcm9020575.

7. Huang $C$, Wang $Y$, Li $X$, et al. Clinical features of patients infected with 2019 novel coronavirus in Wuhan, China. The Lancet. 2020;395:497-506. https://doi.org/10.1016/ S0140-6736(20)30183-5

8. Yin Y, Wunderink RG. MERS, SARS and other coronaviruses as causes of pneumonia. Respirology. 2018;23:130-137. https://doi.org/10.1111/resp.13196

9. Dhama K, Sharun K, Tiwari R, et al. Coronavirus disease 2019-COVID-19.2020a. https://doi: 10.20944/ preprints202003.0001.v1.9

10. Shereen MA, Khan S, Kazmi A, Bashir N, Siddique R. COVID-19 infection: origin, transmission, and characteristics of human coronaviruses. Journal of Advanced Research. 2020;24:91-98. https://doi: 10.1016/j.jare.2020.03.005

11. Fehr AR, Perlman S. Coronaviruses: an overview of their replication and pathogenesis. InCoronaviruses .2015;7:123. Humana Press, New York, NY.

12. Cui J, Li F, Shi ZL. Origin and evolution of pathogenic coronaviruses. Nature reviews Microbiology. 2019;3:18192.https://doi.org/10.1038/s41579-018-0118-9

13. Chan JF, Kok KH, Zhu Z, et al. Genomic characterization of the 2019 novel human-pathogenic coronavirus isolated from a patient with atypical pneumonia after visiting Wuhan. Emerging Microbes and Infections. 2020a;9:221236.

14. Zhu N, Zhang D, Wang W, et al. China Novel Coronavirus Investigating and Research Team. A novel coronavirus from patients with pneumonia in China, 2019. N Engl J Med. 2020a;382:727-733. https:/doi.org/10.1056/ NEJMoa2001017

15. Gralinski LE, Menachery VD. Return of the coronavirus: 2019-nCoV. Viruses. 2020

16. Beniac DR, Andonov A, Grudeski E, Booth TF. Architecture of the SARS coronavirus prefusion spike. Nature Structural \& Molecular Biology. 2006;8:751-2. https://doi.org/ 10.1038/nsmb1123

17. Enserink M. SARS: Chronology of the Epidemic. 2013;339:1266-1271. https://doi.org/10.1126/ science.339.6125.1266

18. Zhou P, Yang XL, Wang XG, et al. A pneumonia outbreak associated with a new coronavirus of probable bat origin. Nature. 2020;579:270. https://doi:10.1038/s41586-0202012-7

19. de Haan CA, Rottier PJ. Molecular interactions in the assembly of coronaviruses. Advances in Virus Research. 2005;1:165-230. https:// doi.org/10.1016/s00653527(05)64006-7

20. Neuman BW, Kiss $G$, Kunding $A H$, et al. A structural analysis of $M$ protein in coronavirus assembly and morphology. Journal of Structural Biology. 2011;174:1122. https://doi:10.1016/j.jsb.2010.11.021

21. Stevens FJ, Argon Y. Protein folding in the ER. In Seminars in Cell \& Developmental Biology. 1999;10:443-454. Academic Press. https://doi.org/10.1006/scdb.1999.0315

22. Wu A, Peng $Y$, Huang B, et al. Genome composition and divergence of the novel coronavirus (2019-nCoV) originating in China. Cell Host and Microbe. 2020a. https://doi.org/10.1016/j.chom.2020.02.001

23. Munster VJ, Koopmans M, van Doremalen N, van Riel $D$, de Wit E. A novel coronavirus emerging in China-key questions for impact assessment. New England Journal of Medicine. 2020;8:692-694. https://doi.org/10.1056/ NEJMp2000929.

24. Wan Y, Shang J, Graham R, Baric RS, Li F. Receptor recognition by the novel coronavirus from Wuhan: an analysis based on decade-long structural studies of SARS coronavirus. Journal of Virology. 2020;17:94. https://doi. org/10.1128/JVI.00127-20

25. Chan JF, Yuan S, Kok KH, et al. A familial cluster of pneumonia associated with the 2019 novel coronavirus indicating person-to-person transmission: a study of a family cluster. The Lancet. 2020b;15:514-23. https://doi. org/10.1016/S0140-6736(20)30154-9

26. Lu X, Zhang L, Du H, et al. SARS-CoV-2 infection in children. New England Journal of Medicine. 2020a;17:1663-1665. https://doi.org/10.1056/NEJMc2005073

27. Wu Y, Xu X, Chen Z, et al. Nervous system involvement after infection with COVID-19 and other coronaviruses. Brain, Behaviour, and Immunity. 2020b;30;1591. https:// doi.org/ 10.1016/j.bbi.2020.03.031

28. Xiang $\mathrm{P}, \mathrm{Xu} X \mathrm{XM}, \mathrm{Gao} \mathrm{LL}$, Wang HZ, Xiong HF, Li RH. First case of 2019 novel coronavirus disease with encephalitis. China Xiv. 2020;10:929-936

29. Mehta P, McAuley DF, Brown M, Sanchez E, Tattersall RS, Manson JJ. COVID-19: consider cytokine storm syndromes and immunosuppression. The Lancet. 2020;28:10331034.

30. Fu Y, Cheng Y, Wu Y. Understanding SARS-CoV-2-mediated inflammatory responses: from mechanisms to potential 
therapeutic tools. Virological Sinica. 2020;3:1-6. https:// doi.org/10.1007/s12250-020-00207-4

31. Coperchini F, Chiovato L, Croce L, Magri F, Rotondi M. The Cytokine storm in COVID-19: An overview of the involvement of the chemokine/chemokine-receptor system. Cytokine \& Growth Factor Reviews. 2020;1:1-8. https//doi.org/10.1016/j.cytogfr.2020.05.003

32. Dhama K, Patel SK, Pathak M, et al. An Update on SARS-COV-2/COVID-19 with Particular Reference on Its Clinical Pathology, Pathogenesis, Immunopathology and Mitigation Strategies- A Review. Preprints. 2020b;30:348 https//doi.org/10.20944/preprints202003.0348

33. Chen N, Zhou M, Dong X, et al. Epidemiological and clinical characteristics of 99 cases of 2019 novel coronavirus pneumonia in Wuhan, China: a descriptive study. The Lancet. 2020b;395:507-13.https://doi.org/10.1016/ S0140-6736(20)30211-7

34. Guan WJ, Ni ZY, Hu Y, et al. Clinical characteristics of coronavirus disease 2019 in China. New England Journal of Medicine. 2020;18:1708-20.

35. Singh RK, Dhama K, Chakraborty S, et al. Nipah virus: epidemiology, pathology, immunobiology and advances in diagnosis, vaccine designing and control strategies-a comprehensive review. Vet Q. 2019;39:26-55. https:// doi.org/10.1080/01652176.2019.1580827

36. Tiwari R, Dhama K, Sharun K, et al. COVID-19: animals, veterinary and zoonotic links. Veterinary Quarterly. 2020;40:169-182

37. Cascella M, Rajnik M, Cuomo A, Dulebohn SC, Di, Napoli R. Features, evaluation and treatment coronavirus (COVID-19). In Stat pearls. 2020

38. Kampf G, Todt D, Pfaender S, Steinmann E. Persistence of coronaviruses on inanimate surfaces and their inactivation with biocidal agents. J Hosp Infect. 2020;104:246-251.

39. Lee PI, \& Hsueh PR. Emerging threats from zoonotic coronaviruses-from SARS and MERS to 2019-nCoV. Journal of Microbiology, Immunology and Infection. 2020. https// doi.org/ 10.1016/j.jmii.2020.02.001

40. Bogoch II, Watts A, Thomas-Bachli A, Huber C, Kraemer $\mathrm{MU}$, Khan K. Pneumonia of Unknown Etiology in Wuhan, China: Potential for International Spread Via Commercial Air Travel. Journal of Travel Medicine. 2020;1:1-3. https// doi.org/10.1093/jtm/taaa008

41. Moore M, Gelfeld B, Adeyemi TO, Okunogb CP. Identifying future disease hot spots: infectious disease vulnerability index. Rand Health Quarterly. 2017;6:3. https//doi.org/ 10.7249/RR1605

42. Coronavirus outbreak: What are the stages of transmission and what they mean, 2020; The four stages of Covid-19 transmission \& why India maintains it is not yet in stage 3, 2020.

43. Dowell SF, Simmerman JM, Erdman DD, et al. Severe acute respiratory syndrome coronavirus on hospital surfaces. Clinical Infectious Diseases. 2004;5:652-657. https://doi. org/10.1086/422652

44. Otter JA, Donskey C, Yezli S, Douthwaite S, Goldenberg SD, Weber DJ. Transmission of SARS and MERS coronaviruses and influenza virus in healthcare settings: the possible role of dry surface contamination. Journal of Hospital Infection. 2016;3:235-50. https://doi.org/ 10.1016/j. jhin.2015.08.027

45. Belser JA, Rota PA, Tumpey TM. Ocular tropism of respiratory viruses. Microbiol. Mol. Biological Review. 2013;1:144-56. https://doi.org/10.1128/MMBR.0005812

46. Lu CW, Liu XF, Jia ZF. 2019-nCoV transmission through the ocular surface must not be ignored. Lancet (London, England). 2020b;395(10224):e39. https//doi. org/10.1016/S0140-6736 (20)30313-5

47. Holshue ML, DeBolt C, Lindquist S, et al. First case of 2019 novel coronavirus in the United States. New England Journal of Medicine. 2020. https//doi.org/ 10.1056/ NEJMoa2001191

48. Lee PI, Hsueh PR. Emerging threats from zoonotic coronaviruses-from SARS and MERS to 2019-nCoV. Journal of Microbiology, Immunology and Infection. 2020. https//doi.org/ 10.1016/j.jmii.2020.02.001

49. La Rosa G, Bonadonna L, Lucentini L, Kenmoe S, Suffredini E. Coronavirus in water environments: Occurrence, persistence and concentration methods-A scoping review. Water Research. 2020;115899. https//doi.org/10.1016/j. watres.2020.115899

50. Ahmed W, Angel N, Edson J, et al. First confirmed detection of SARS-CoV-2 in untreated wastewater in Australia: A proof of concept for the wastewater surveillance of COVID-19 in the community. Science of Total Environment. 2020;728:138764. https//doi.org/ 10.1016/j.scitotenv.2020.138764

51. Medema G, Heijnen L, Elsinga G, Italiaander R, Brouwer A. Presence of SARS-Coronavirus-2 in sewage. MedRxiv. 2020. https//doi.org/ 10.1101/2020.03.29.20045880

52. Wang J, Feng $\mathrm{H}$, Zhang $\mathrm{S}$, et al. SARS-CoV-2 RNA detection of hospital isolation wards hygiene monitoring during the Coronavirus Disease 2019 outbreak in a Chinese hospital. International Journal of Infectious Diseases. 2020a;94:103-106. https//doi.org/ 10.1016/j. ijid.2020.04.024

53. Ali M, Zaid M, Saqib MAN, Ahmed H, Afzal MS. SARSCoV-2 and the Hidden Carriers-Sewage, Feline, and Blood Transfusion. Jounral Med Virol. 2020. https//doi.org/ 10.1002/jmv.25956

54. Bonato G, Dioscoridi L, Mutignani M. Faecal-oral transmission of SARS-COV-2: practical implications. Gastroenterology. 2020;S0016-5085(20)30449-2. https:// doi.org/ 10.1053/j.gastro.2020.03.066

55. Tian S, Hu W, Niu L, Liu H, Xu H, SY, Xiao. Pulmonary pathology of early phase 2019 novel coronavirus (COVID-19) pneumonia in two patients with lung cancer. Journal of Thoracic Oncology. 2020;15:700-704. https:// doi.org/10.1016/j.jtho.2020.02.010

56. Han Y, Yang H. The transmission and diagnosis of 2019 novel coronavirus infection disease (COVID-19): A Chinese perspective. Journal of Medical Virology. 2020;92:639-44. https://doi.org/10.1002/jmv.25749

57. Wei M, Yuan J, Liu YU, et al. Novel coronavirus infection in hospital-ized infants under 1 year of age in China. JAMA. 2020;14:14 https://doi.org/ 10.1001/jama.2020.2131

58. Zhu $\mathrm{H}$, Wang L, Fang $\mathrm{C}$, et al. Clinical analysis of 10 neonates born to mothers with 2019-nCoV pneumonia. Trans/ational Pediatrics. 2020b;1:51.https://doi.org/ 10.21037/tp.2020.02.06

59. Levine S, Bonner A, Perry A, Melady D, Unroe KT. COVID-19 in Older Adults: Transfers Between Nursing Homes and Hospitals. 2020.https://doi.org/ 10.15585/ 
mmwr.mm6912e2

60. Applegate WB, Ouslander JG. COVID-19 presents high risk to older persons. Journal of the American Geriatrics Society. 2020;68:681. https://doi.org/ 10.1111/jgs.16426

61. Chen $\mathrm{H}$, Guo J, Wang C, et al. Clinical characteristics and intrauterine vertical transmission potential of COVID-19 infection in nine pregnant women: a retrospective review of medical records. The Lancet. 2020;7:809-15.https:// doi.org/10.1016/S0140-6736(20)30360-3

62. Favre G, Pomar L, Musso D, Baud D. 2019-nCoV epidemic: what about pregnancies?. The Lancet. 2020. https://doi. org/10.1016/S0140-6736(20)30311-1

63. Patel SK, Pathak M, Tiwari $R$, et al. A vaccine is not too far for COVID-19. J Infect Dev Ctries. 2020 (accepted, in press JIDC \#12744). https://doi.org/10.3855/jidc.12425

64. Gul MH, Htun ZM, Shaukat N, Imran M, Khan A. Potential specific therapies in COVID-19. Ther Adv Respir Dis. 2020;14 https://doi.org/10.1177/1753466620926853

65. Vellingiri $B$, Jayaramayya $K$, lyer $M$, et al. COVID-19: A promising cure for the global panic. Sci Total Environ. 2020;725:138277. https://doi.org/10.1016/j. scitotenv.2020.138277

66. Centre for Disease Control and Prevention (CDC). 2020. 2019 Novel Coronavirus - Prevention \& Treatment. https://www.cdc.gov/coronavirus/2019ncov/about/ prevention-treatment.html 2020

67. WHOb. 2020, Laboratory testing for coronavirus disease 2019 (COVID-19) in suspected human cases: interim guidance, 2 March 2020. World Health Organization, 2020.

68. WHOc. List of Blueprint priority diseases 2018 [Available from: www.who.int/ blueprint/priority-diseases/en

69. Cheng AC, DA Williamson. An outbreak of COVID-19 caused by a new coronavirus: what we know so far. Medical Journal of Australia. 2020c;9:393-394. https:// doi.org/10.5694/mja2.50530

70. Chen H, Guo J, Wang C, et al. Clinical characteristics and intrauterine vertical transmission potential of COVID-19 infection in nine pregnant women: a retrospective review of medical records. The Lancet. 2020;395:809-15. https:// doi.org/10.1016/S0140-6736(20)30360-3

71. Kaplan EH. Containing 2019-nCoV (Wuhan) coronavirus. Health Care Manag Science. 2020. https://doi. org/10.1007/s10729-020-09504-6

72. Omrani AS, Saad MM, Baig K, et al. Ribavirin and interferon alfa-2a for severe Middle East respiratory syndrome coronavirus infection: a retrospective cohort study. The Lancet Infectious Diseases. 2014;11:10901095. https://doi.org/10.1016/S1473-3099(14)70920-X

73. Li H, Wang YM, Xu JY, Cao B. Potential antiviral therapeutics for 2019 Novel Coronavirus. Zhonghua jie he he hu xi za zhi= Zhonghua jiehe he huxi zazhi= Chinese journal of tuberculosis and respiratory diseases. 2020;43:E002-. https://doi.org/10.3760/ cma.j.issn.1001-0939.2020.0002

74. Chu CM, Cheng VC, Hung IF, et al. Role of lopinavir/ ritonavir in the treatment of SARS: initial virological and clinical findings. Thorax. 2004;3:252-6. https://doi.org/ 10.1136/thorax.2003.012658

75. Arabi YM, Alothman A, Balkhy HH, et al. Treatment of Middle East Respiratory Syndrome with a combination of lopinavir-ritonavir and interferon- $\beta 1 \mathrm{~b}$ (MIRACLE trial): study protocol for a randomized controlled trial. Trials. 2018;81. https://doi.org/10.1186/s13063-017-2427-0

76. Lu H. Drug treatment options for the 2019-new coronavirus (2019-nCoV). Biosci Trends. 2020. https:// doi.org/10.5582/bst.2020.01020

77. NHC. 2020a. Diagnosis and Treatment of Pneumonia Caused by 2019- nCoV (version 5).http://www.nhc. gov.cn/yzygj/s7653p/202002/3b09b 894ac9b4204a 79db5b8912d4440.shtml (accessed February 5, 2020). (in Chinese).

78. NHC. 2020b. National Health Commission. Interpretation of the Sixth Edition of the Guidance for COVID-19: Prevention, Control, Diagnosis, and Management. http://www.nhc. gov.cn/xcs/ fkdt/202002/54e1ad5c2aac45c19eb541799bf6 37e9. shtml (accessed April 2, 2020). (in Chinese)

79. Costanzo M, De Giglio MAR, Roviello GN. SARS CoV-2: Recent Reports on Antiviral Therapies Based on Lopinavir/ Ritonavir, Darunavir/Umifenovir, Hydroxychloroquine, Remdesivir, Favipiravir and Other Drugs for the Treatment of the New Coronavirus. Curr Med Chem. 2020. https:// doi.org/10.2174/0929867327666200416131117

80. Coleman CM, Sisk JM, Mingo RM, Nelson EA, White $J M$, Frieman MB. Abelson kinase inhibitors are potent inhibitors of severe acute respiratory syndrome coronavirus and Middle East respiratory syndrome coronavirus fusion. J Virol. 2016;90:8924-8933. https:// doi.org/10.1128/JVI.01429-16

81. Dong L, Hu S, Gao J. Discovering drugs to treat coronavirus disease 2019 (COVID-19). Drug discoveries and therapeutics. 2020;14:58-60. https://doi.org/ 10.5582/ddt.2020.01012

82. Gao J, Tian Z, Yang X. Breakthrough: Chloroquine phosphate has shown apparent efficacy in treatment of COVID-19 associated pneumonia in clinical studies. Biosci Trends. 2020;14:72-73. https://doi.org/10.5582/ bst.2020.01047

83. Wang $M$, Cao R, Zhang L, Yang X, Liu J, Xu M, Shi Z, Hu Z, Zhong W, Xiao G. Remdesivir and chloroquine effectively inhibit the recently emerged novel coronavirus (2019nCoV) in vitro. Cell Research. 2020b.3:269-271

84. Patri A, Fabbrocini G. Hydroxychloroquine and ivermectin: a synergistic combination for COVID-19 chemoprophylaxis and/or treatment? I Am Acad Dermatol. 2020:S0190-9622(20)30557-0. https://doi. org/10.1016/j.jaad.2020.04.017

85. Ke YY, Peng TT, Yeh TK, Huang WZ, Chang SE, Wu SH, Hung HC, Hsu TA, Lee SJ, Song JS, Lin WH, Chiang TJ, Lin $\mathrm{JH}$, Sytwu HK, Chen CT. Artificial intelligence approach fighting COVID-19 with repurposing drugs. Biomed Jounral, 2020. https://doi.org/10.1016/j.bj.2020.05.001

86. Casadevall A, Pirofski LA. The convalescent sera option for containing COVID-19. J Clin Invest. 2020;4:1545-1548. https://doi.org/10.1172/JCl138003

87. Kumar GV, Jeyanthi V, Ramakrishnan S. A short review on antibody therapy for COVID-19. New Microbes and New Infections. 2020; 35:1-4. https://doi.org/10.1016/j. nmni.2020.100682

88. Shanmugaraj B, Siriwattananon K, Wangkanont K, Phoolcharoen W. Perspectives on monoclonal antibody therapy as potential therapeutic intervention for Coronavirus disease-19 (COVID-19). Asian Pac J Allergy 
Immunology. 2020;1:10-8.https://doi.org/10.12932/ AP-200220-0773

89. Zumla A, Hui DS, Azhar El, Memish ZA, Maeurer M. Reducing mortality from 2019-nCoV: host-directed therapies should be an option. Lancet. 2020;395:35-36. https://doi.org/10.1016/S0140-6736 (20)30305-6

90. Zhang L, Yu J, Zhou Y, Shen M, Sun L. Becoming a Faithful Defender: Traditional Chinese Medicine against Coronavirus Disease 2019 (COVID-19). American Journal of Chin Medical. 2020:1-15. https://doi.org/10.1142/ S0192415X2050038X
91. Naja F. and Hamadeh R. Nutrition amid the COVID-19 pandemic: a multi-level framework for action. European Journal of Clinical Nutrition, 2020:1-5. https://doi.org/ 10.1038/s41430-020-0634-3

92. Galanakis CM. The Food Systems in the Era of the Coronavirus (COVID-19) Pandemic Crisis. Foods. 2020; 4:523. https://doi.org/10.3390/foods9040523

93. Dhama K, Sharun K, Tiwari R, Dadar M, Malik YS, Singh KP, Chaicumpa W. COVID-19, an emerging coronavirus infection: advances and prospects in designing and developing vaccines, immunotherapeutics, and therapeutics. Hum Vaccin Immunother. 2020c:1-7. https://doi.org/10.1080/21645515.2020.1735227 